
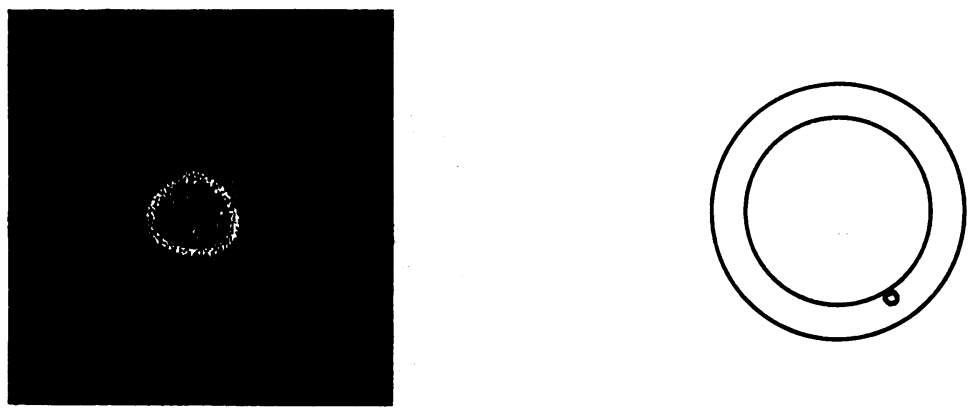

had obviously no connection with the interstitial opacity in the deeper layers of the cornea. There was no suggestion that they were due to injury or deposits of lead or other change, and I am inclined to think with Coats that the condition might be congenital.

\title{
HAEMORRHAGE INTO A PROLAPSED VITREOUS POUCH
}

BY

\section{T. HARRISON BUTLER}

BIR M I NGHAM

THE exact structure of the vitreous is still open to discussion, and any evidence which bears upon the subject is of value.

Examination of the vitreous with the slit-lamp shows a series of waving membranes one behind the other. When the eye is moved, these membranes float up and slowly return to their vertical position. This is the usual appearance, but variations are common. In some cases the vitreous seems much more homogeneous, in a few it appears to be full of fibrils like cotton threads. When the vitreous degenerates the floating membranes disappear; the structure is simplified; and instead of membranes we see floating strands and particles.

Duke-Elder and others think that the membranes are merely optical phenomena. Ida C. Mann believes that there are real membranes in the central part of the vitreous representing Cloquet's Canal. The more one observes these membranes and their behaviour, the more one feels that they are real anatomical structures; whether they fill the whole vitreous or merely the central visible part must be a matter of conjecture.

I have recently had under my care at The West Bromwich Hospital, a case with features which greatly strengthen the view 
that there are tangible membranes. If they will form a bag which holds blood, then the idea that they are optical illusions falls to the ground.

The following is the case in point :-

B. H., aged 66 years, had a simple extraction with corneal section performed by the late Mr. Martin Young in 1926. Although the media were quite clear and the fundus perfectly normal in appearance, the best acuity obtained was $6 / 60$. The other eye contained a mature cataract.

On May 25, 1932, I performed a preliminary iridectomy.

Convalescence was normal till June 9 , when he was found to have a large hyphaema with haemorrhages on the iris, and ciliary injection. These absorbed, and the patient was discharged with a clean coloboma and no sign of inflammation or haemorrhage.

On July 21 I extracted the left lens using the usual section. There was no haemorrhage at the operation which was in every respect a normal one. On July 23 the dressings were changed. The eye was quiet and there was no haemorrhage. There was no change in this favourable aspect till July 28 , when the patient's temperature suddenly rose and the anterior chamber was seen to be half-full of blood. This was completely absorbed but recurred, and the pupil became contracted. On August 10 all the blood had again become absorbed, but there were now some posterior synechiae and the pupil failed to dilate with atropine. He was now discharged from the hospital. On September 13 the eye was free from inflammation and blood, but the pupil was occluded by an opaque membrane. On September 19 discission was performed and a clear

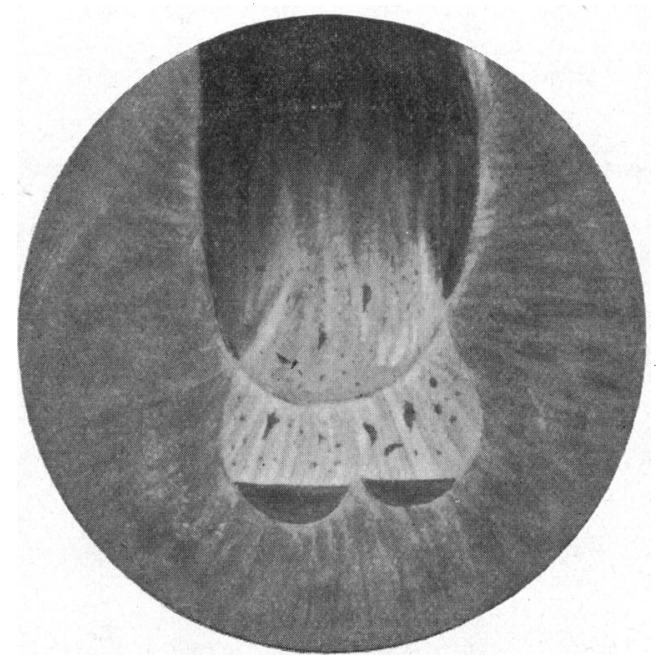


black pupil obtained. This operation was followed by a small hyp̉haema, but it rapidly absorbed, and the patient was discharged. The fundus could not be seen because of opacity in the vitreous.

November 3. The best acuity is fingers at half a metre. There is a collection of blood in the anterior chamber which appears to be contained in a pouch of prolapsed vitreous, but its exact situation cannot be decided without a slit-lamp, which the hospital does not at this time possess. On November 12 there was still blood in the anterior chamber. This blood again became absorbed.

On December 22 the patient turned up again and said that his sight, which had been improving, had suddenly got much worse again. The West Bromwich Hospital had now obtained a Mackie Slit-Lamp. Examination with this instrument showed a most. interesting state of affairs: The eye was free from any sign of inflammation. There was no free blood in the anterior chamber or on the iris. There were no blood cells in the aqueous. There was a prolapse of vitreous into the anterior chamber forming a biloculate pouch. The pouch is half-full of fresh blood forming a double collection. The inside of the pouch is here and there smeared with bright blood. The vitreous shows the usual deposit of brown pigment particles on its surface. 'This examination shows that the blood came from the interior of the eye, and not from the iris or any structure in the anterior chamber. It also quite definitely demonstrates that the vitreous can prolapse in the form of a pouch which is capable of holding fluids. This cannot be a hyaloid membrane, for this, if present, was most certainly ruptured by the discission, which was a deep one. It would seem to prove that the vitreous either contains membranes or is capable of rapidly forming them when prolapsed.

I have now had an opportunity of thoroughly testing the Mackie Slit-Lamp and I find it a perfectly satisfactory instrument for ordinary clinical work. It is constructed on sound principles in that the light and the microscope are entirely free from each other. The microscope is a good one, the illumination is sufficient, and the slit can be graduated to the required extent. It is convenient to use, and the lamp can be removed from one side to the other. It adequately takes the place of the Zeiss instrument and costs little more than a third of its price.

The appended drawing shows the appearance of the blood and of the biloculate pouch.

I am at a loss to explain the recurrent haemorrhage. There was none at the first extraction, but this may have been avoided by the strictly corneal section. The patient tells me that at one time his nose used to bleed freely. There is no family history of haemophilia. Nor can I understand why the vision of the right eye is 
so poor. I have seen several cases where after an ideal extraction the sight was very bad, although the fundus was quite normal.

April 6, 1933. The patient attended for re-examination. Most of the blood has now been absorbed, but each pouch still contains a little. The fundus can be clearly seen and the corrected vision is $6 / 18$.

\title{
DIABETIC CATARACT
}

BY

\author{
LT.-Col. E. O'G. KiRWAN, I.M.S. \\ PROFESSOR OF OPHTHALMOLOGY, MEDICAL COLLEGE HOSPITAL, \\ CALCUTTA
}

In Bengal, diabetes is a very common disease and usually develops in early middle life, but most of the cases that one sees are in the fifth and sixth decades. The disease is much more common in men than in women, and principally affects the educated middle class, which includes such people as lawyers, doctors, landowners, business men, clerks, and so on. It is not often seen among the peasants who have to work hard and take a lot of exercise. Women seldom suffer from diabetes. The disease cannot be said to be due to an excessive amount of carbohydrate food, as women eat as much carbohydrate as men. Diabetes in Bengal is usually associated with over-eating, lack of exercise, and oral sepsis, which result in dyspepsia, and there is usually mental worry. Large numbers of Bengalis are chronic dyspeptics, so that their food is not properly assimilated; they take very little exercise, and spend daily long hours at their business or profession, which must eventually result in mental strain. In contrast, their women folk have plenty of time to take their food, and in one way or another, take a considerable amount of exercise; but women who undertake the duties of men, such as looking after a business or doing professional work, are not exempt from diabetes, as their physical and mental condition simulate those of men. Heredity is an important factor in diabetes in Bengal, and frequently one comes across the disease in several members of the same family.

The ocular complications of diabetes are many, such as changes in refraction, paralysis of muscles, amblyopia, iritis, retrobulbar neuritis, retinitis, retinal lipaemia, haemorrhages, cataract, glaucoma and xanthelasma. In Bengal, far and away the commonest ocular complication is retinal haemorrhages.

As diabetes mellitus is probably more prevalent in Bengal than in any other part of the world, one would expect to see a large number 